\title{
Qiraah Alquran Dengan Nagham Ajam - Lagam Jawa; Kasus Isra' Mi'raj di Istana Negara, Jum'at, 15 Mei 2015
}

\author{
(Qiraah Koran By Nagham Ajam - Lagam Java; Case Isra 'Mi'raj At The State
}

Palace On Friday, May 15, 2015)

\author{
Qosim Arsadani \\ Universitas Islam Negeri Syarif Hidayatullah Jakarta \\ Jl. Ir. H. Juanda No. 95 Ciputat Tangsel \\ E-mail: qosimarsadani@gmail.com \\ doi $\underline{10.15408 / \text { sjsbs.v3i1.3320 }}$
}

\begin{abstract}
:
Every Muslim would agree that the Koran is the holy book were wonderful. He will be more beautiful when it is read beautifully by using Nagham and a melodious voice. By reading the Koran is mutawaatir means that from the beginning the angel Gabriel received it from Allah which is then conveyed to the Holy Prophet so were messengers to convey back to friends and so on in the history of the turn and the different traffic generation is the same. New problems arise when the Koran is read using Java Nagham. Therefore this study want to discuss more in depth about the law.
\end{abstract}

Keywords: Koran, Qiroah and Nagham

\begin{abstract}
Abstrak:
Setiap muslim pasti sepakat bahwa Alquran kitab suci yang indah. Ia akan menjadi semakin indah apabila dibaca secara indah dengan menggunakan nagham atau lagam dan suara yang merdu. Secara bacaan Alquran bersifat mutawatir artinya sejak dari awal malaikat Jibril menerimanya dari Allah SWT yang kemudian disampaikan kepada Rasulullah Saw begitu pula rasul dalam menyampaikan kembali kepada para sahabat dan begitu seterusnya dalam lintas sejarah pergantian dan berbedanya generasi adalah sama. Permasalahan baru muncul ketika Alquran dibaca dengan menggunakan Nagham Jawa. Oleh karenanya penelitian ini ingin membahas lebih mendalam tentang hukumnya.

Kata Kunci: Alquran, Qiroah dan Nagham
\end{abstract}

* Diterima tanggal naskah diterima: 11 Maret 2016, direvisi: 21 April 2016, disetujui untuk terbit: 22 Mei 2016. 


\section{Pendahuluan}

Allah SWT telah menyampaikan kalam-Nya (Alquran) dalam bahasa arab agar kalian berfikir-memahami: انا انزلناه عربيا لعلكم تعقلون - “Sesungguhnya Kami menurunkannya berupa Al Quran dengan berbahasa Arab, agar kamu memahaminya"(Q.S.Yusuf: 12:2). Bahkan lebih dari itu menurut imam Muhammad bin Idris al-Syafi'i seluruh kitab Samawi (sebutan kitab yang berdasarkan wahyu; zabur, taurat dan injil) diturunkan dalam bahasa arab. ${ }^{1}$ Kalamullah adalah kalam agung yang nilai dan posisinya sama dengan pemiliknya, yaitu Allah Jalla Jalaluhu. Kalam Allah SWT menurut para ulama ada yang bersifat Manthuq - terucap dan ada yang bersifat Ghairu Manthuq- tidak terucap.

Kalamullah yang Ghairu Manthuq lazim disebut dengan Ayat Kauniyah berupa jagat raya. Kalam Allah SWT yang terucap dalam bentuk kitab wajib diimani dan dipercaya oleh setiap orang mukmin karena ia bagian dari rukun iman yang enam. Disebutkan dalam sebuah hadist dari sahabat Umar bin Khattab ra. Bahwa suatu hari Rasulullah SAW kedatangan seorang tamu yang berpakaian serba putih, rambutnya hitam serta tidak diketahui dari mana asal datangnya tamu tersebut oleh para sahabat. Kemudian tamu itu duduk dihadapan Rasulullah SAW seraya menempelkan kedua lututnya dengan lutut Rasulullah SAW dan meletakkan kedua telapak tangannya di atas kedua pahanya, kemudian dia bertanya; wahai Rasulullah SAW, apa itu iman? Rasulullah SAW menjawab; iman itu adalah engkau percaya kepada Allah, kepada para malaikat, kitab-kitab-Nya, percaya kepada para rasul-Nya, percaya dengan hari akhir, dan engkau percaya dengan taqdir, baik dan jeleknya. ${ }^{2}$ Kalam Allah SWT yang manthuq-terucap terbagi menjadi dua katagori, yaitu kitab dan suhuf (lembaran-lembaran). Informasi ini langsung disampaikan oleh Allah SWT dalam beberapa ayat Alquran. Khusus untuk suhuf diantaranya dapat kita lihat dan baca dalam surat al-A'laa (87): 19 atau ayat terakhir dari surat tersebut, yaitu "Suhuf Ibrahim dan Musa".

Kalam Allah SWT yang berupa kitab yang menjadi bagian dari rukun iman sebagaimana disebutkan dalam hadist di atas ada empat buah, yaitu; 1 . Taurat diturunkan kepada Nabi Musa as., 2. Zabur diturunkan kepada Nabi Dawud as., 3. Injil diturunkan kepada Nabi Isa as., dan 4. Alquran diturunkan kepada nabi Muhammad SAW. ${ }^{3}$ Karena beriman dengan kitab adalah bagian dari rukun iman, maka cara pendekatannya adalah dengan ta'abbudi yaitu sikap menerima apa adanya tanpa reserve dan tanpa sikap kritis sebagai realisasi

${ }^{1}$ Al-Syafi'i, Abu Abdullah Muhammad bin Idris. Ahkam al-Qur'an, (Beirut: Dar al-Fikr, 1997 H. - 1418 M.), j. 1., h. 29

${ }^{2}$ Imam Muslim, Shahih Muslim, (Mesir: Isa al-Babi al-Halbi wa Syirkah, tth.), h. 22

3 Nashr bin Muhammad al-Hanafi al-Samarqandi, Qathr al-Ghaist fi Syarh Abi Laist, (Surabaya: Said bin Nabhan wa Auladuh, tth), h. 7 
ketertundukan (ibadah) seseorang kepada Allah SWT sebagai Khaliqnya. Sikap ta'abbudi ini harus dipunya dan dipahami oleh setiap muslim karena adanya pengetahuan tentang kitab tersebut bersifat Ma'lum min al-Din bi al-Dlaruri, sesuatu yang bersifat given dan dogmatis.

Alquran sebagai salah satu kitab yang diturunkan terakhir dan tentu kepada nabi terakhir, penutup para nabi dan rasul-khatam al-Ambiya wa alMursalin, Nabi Muhammad bin Abdullah bin Abdul Muthalib al-Quraisyi yang nuzul - turun pertama pada saat Nabi Muhammad SAW sedang beribadah tahannus (kontemplasi) di gua Hira pada tahun 611 M. disaat usianya mencapai 40 tahun. Memang tidak bias dipungkiri bahwa satu rasul dengan rasul lainnya ada interdependensi dan talenta yang menghubungkan, baik secara darah seperti dari Nabi Ibrahim punya anak Ishaq dan Ismail, Ya'qub, Yusuf dan seterusnya ataupun lainnya terutama kesamaan visi dan misi yang diembannya, yaitu menyampaikan risalah tauhid dan monotheisme. Visi dan misi risalah tauhid dan monotheisme para rasul yang ternyata merupakan perjanjian antara manusia dengan Allah SWT dengan MoU abadi sejak mereka masih berada di alam ruh. Kita perhatikan Firman Allah SWT dalam Q.S. al-'Araf (7): 172.

“Dan (ingatlah), ketika Tuhanmu mengeluarkan keturunan anak-anak Adam dari sulbi mereka dan Allah mengambil kesaksian terhadap jiwa mereka (seraya berfirman): "Bukankah aku ini Tuhanmu?" mereka menjawab: "Betul (Engkau Tuban kami), Kami menjadi saksi". (kami lakukan yang demikian itu) agar di hari kiamat kamu tidak mengatakan: "Sesungguhnya Kami (Bani Adam) adalah orang-orang yang lengah terhadap ini (keesaan Tuhan)."

Kesamaan visi dan misi para manusia pilihan Tuhan ini dalam mengemban risalah tauhid menjadikan satu dengan lainnya bagaikan untaian mutiara yang indah dan apik, satu berkelindan dengan lainnya, semua dalam rangka menuju Yang Satu. Betapa informasi sudah langsung disampaikan oleh sumber informasi yang sangat otoritatif dan pasti valid, Allah SWT dalam Alquran surat al-Ambiyaa (21): 25.

“Dan Kami tidak mengutus seorang Rasulpun sebelum kamu melainkan Kami wahyukan kepadanya: "Bahwasanya tidak ada Tuhan (yang hak) melainkan Aku, Maka sembahlah olehmu sekalian akan Aku".

Diantara apologistik keberhasilan produktifitas serta suksesnya dakwah para rasul, ternyata orang-orang yang dipercaya untuk menyampaikan risalah Ilahiyyah, misi ketuhanan dengan membawa syariat, adalah mereka diutus sesuai dengan bahasa dan kondisi masyarakatnya masing-masing. Allah SWT telah menginformasikan hal itu langsung kepada kita sebagaimana dapat kita baca dalam firman-Nya.

"Kami tidak mengutus seorang rasulpun, melainkan dengan bahasa kaumnya, supaya ia dapat memberi penjelasan dengan terang kepada mereka. Maka Allah menyesatkan siapa yang Dia kehendaki, dan memberi petunjuk kepada siapa 
yang Dia kehendaki. dan Dia-lah Tuhan yang Maha Kuasa lagi Maha Bijaksana." (Q.S. Ibrahim: 14:4)

Allah SWT Maha Bijaksana, Maha Mengetahui juga Maha Mengatur dalam menurunkan syariat dan segala ketentuan yang menyangkut manusia tidak begitu saja dengan sifat Maha Perkasa-Nya. Sebaliknya Dia menurunkan dan menyampaikan-Nya sesuai situasaiN dan kondisi masyarakat dalam setiap generasinya. Suatu syariat yang diperuntukkan untuk suatu masyarakat belum tentu syariat tersebut masih eksis dan dipertahankan dalam generasi masyarakat berikutnya, seperti khitan yang disyariatkan sejak Nabi Ibrahim hingga kini, lain dari khitan adalah pernikahan yang ternyata sudah ada revisi dari banyak segi. Betapa indah perumpamaan yang menyatakan, bahwa satu periode rasul dengan periode rasul berikutnya adalah ibarat orang yang membangun sebuah bangunan yang apik, indah dan serasi sampai titik bata terakhir. Rasulullah SAW bersabda, hadist dari sahabat Abu Hurairah (H.R. Bukhari) :4

\begin{abstract}
"Sesungguhnya perumpamaan saya dan para nabi sebelum saya adalah seperti seorang membangun rumah, dia membangun secara bagus dan indah terus tertinggal satu bata, kemudian manusia mengelilingi (memperhatikan) dan mereka heran karenanya, mereka berkata, coba batu ini diletakkan, saya adalah batu itu, dan saya adalah penutup para $\mathrm{n}$
\end{abstract}

\title{
Alquran itu ya Qiroah - Bacaan
}

Allah SWT itu adalah Tuhan Yang Maha Esa, Tuhan pasti di luar alam, karena memang Dia tidak butuh tempat sebagaimana jirim-makhluk yang selalu membutuhkan tempat sekedar cukup seberapa besar dirinya, karena Allah Jalla Sya'nuhu di luar alam agar Dia dikenal manusia yang berada di dalam alam, maka Allah SWT memperkenalkan diri-Nya dan fihak yang Dia percaya untuk menyampaikannya itu disebut dengan Rasulullah (utusan Allah). Untuk membangun komunikasi tentu harus ada cara yang dipakai, satu diantaranya adalah dengan bahasa verbal yang disebut dengan Kalamullah (ucapan/firman Allah).

Kalamullah yang berupa Alquran secara jumlah surat dalam mushaf Usmani bisa kita identifikasi jumlahnya yaitu 114 surat, walaupun faktualnya secara kuantitas para ulama berbeda pendapat tentang besaran jumlah ayat apalagi hurufnya, sebagaimana dijelaskan oleh Muhammad Amin Suma yang mengutip beberapa pendapat ulama, yaitu menurut ulama Madinah jumlah ayatnya sebanyak 6.210, ulama Basrah sebanyak 6.204, ulama Syam 6.226, ulama Kufah 6.217 dan menurut Ibn Abbas sebanyak 6.616.5 Kalamullah yang manthuq

\footnotetext{
4. H, 1864.

${ }^{4}$ Imam Ismail bin Ibrahim bin Mughirah al-Bukhari, Shahih Bukhari, (Mesir: Dar Kutub), j.

${ }^{5}$ Muhammad Amin Suma, Studi Ilmu-ilmu Al-Qur'an, (Jakarta: Pustaka Firdaus, 2000), j. 1, h. $79-80$
} 
ini berbeda dengan ayat kauniyah yang berbentuk jagat alam raya ini, ayat-ayat kauniyah ini kalau kita lihat secara jenis mungkin bias kita lakukan tetapi bentuk rincian satuan masing-masing dalam realitasnya tentu menjadi sangat sulit kalau tidak dikatakan mustahil untuk kita bisa mengetahui detailnya. Tulisan ini berusaha untuk menelisik dan melihat lebih dalam pendapat ulama tentang Alquran dan bacaannya. Sebagaimana dipahami bahwa kalam Allah SWT dalam system credo-keyakinan Ahl al-Sunnah wa al-Jama'ah adalah bersifat tanpa suara dan juga tanpa huruf (بلا صوت ولا حرف ), hal ini identik dengan realitas wujud Allah SWT itu sendiri yang bersifat Berbeda dengan makhluk ( بلان (مخالفة للحوادث).6 Di dalam memahami firman Allah SWT ayat ke 2 dalam surat Yusuf (12): "Sesungguhnya Kami menurunkannya berupa al-Quran dengan berbahasa Arab, agar kamu memahaminya".

Para ulama berbeda pendapat, bahwa kalam Allah SWT yang berupa Alquran itu diturunkan dan disampaikan dalam bahasa Arab. Konsekwensinya maka seluruh aspek terkait dengan Alquran harus menggunakan standar bahasa arab, bukan bahasa lainnya. Barang siapa berpendapat lain, maka dia salah. Demikian kata Abu Ubaidah juga Ibnu Faris. ${ }^{7}$ Kalau kita telisik pendapat para ulama mengenai Alquran secara etimologi - arti kebahasaan ternyata para ulama berbeda pendapat tentang ashaliyah-otentikasi lafal Alquran itu sendiri. Secara bahasa ada yang mengatakan bahwa lafal Alquran itu asli tetapi ada juga yang berpendapat tidak asli, tetapi sebaliknya bahwa kata Alquran itu diambil dan mempunyai akar kata-musytaq (مشتق) dari kata-kata yang lain.

Perbedaan pendapat tentang ashaliyah kata Alquran ini disamping masalah penulisannya juga dari asal muasal kata Alquran itu sendiri, begitu juga dalam pengucapannya. Ada yang berpendapat Alquran secara bahasa mempunyai huruf hamzah - mahmuz (مهموز) ada juga yang mengatakan tidak ada hamzahnya- ghairu mahmuz (غير مهموز). Menurut Imam Muhammad bin Idris al-Syafi'i (w.155 H.) atau yang lebih dikenal dengan panggilan imam Syafi'i, ${ }^{8}$ Alquran dalam penulisan ataupun pengucapannya sama yaitu tanpa hamzah ghairu mahmuz (غير مهوز), juga tidak mempunyai akar kata - ghairu musytaq ( غير ) مشتق Bagi imam Syafi'i, Alquran adalah nama kitab suci yang Allah SWT turunkan kepada nabi terakhir, nabi Muhammad SAW sebagaimana kitab Taurat kepada nabi Musa, kitab Zabur kepada nabi Dawud dan kitab Injil kepada nabi Isa (semoga shalawat dan salam Allah untuk semua mereka, keluarga, sahabat, kita juga semua para pengikut hingga akhir zaman, Amin) sehingga penulisan dan pengucapannya adalah al-Quran (القران). Sedangkan Imam al-Farra', Yahya

${ }^{6}$ Muhammad al-Sanusi, Hasyiyah al-Dasuqi 'ala Um al-Barahain, (Singapura, Jeddah: AlHaramain, tth), h. 112. Lihat juga pada; Abdullah al-Syarqawi, Al-Syarqawi 'ala al-Hud-Hudi, (Semarang: Maktabah wa Matba'ah Keluarga, tth.), h. 73-74 j. 1 , h. 427

7 Abdurrahman al-Suyuthi, Al-Itqan fi Ulum al-Qur'an, (Beirut: Dar al-Fikr, 1996M./1416H.),

8 Subhi Shalih, Mabahist fi Ulum al-Qur'an, (Beirut: Dar al-Ilm lil Malayin, tth),h. 18 
bin Ziyad al-Dailami salah seorang ahli nahwu dari Kufah berpendapat, bahwa lafal Alquran itu tidak asli tetapi mempunyai akar kata - musytaq (مشتق) (مشن) dari kata qa-ra-in (قرائن) yang merupakan kata jama' (plural) dari kata qarinah (قرينة) yang berarti tanda atau simbul, karena itu huruf hamzah dalam lafal Alquran adalah asli. ${ }^{9}$ Namun demikian menurut imam al-Zajjaj, Ibrahim bin al-Sirri (w. 311H.), lafal Alquran secara penulisan dan pengucapannya mempunyai hamzah (مهموز) juga mempunyai akar kata ( مشتق ) dari kata qar-u (قرء) yang berarti al-Jam'u (الجمع) - mengumpulkan atau menghimpun, ikut timbangan kata (wazan) fu'lan (فعلان); hal ini disebabkan isi Alquran itu mengumpulkan dan menghimpun isi kitabkitab samawi terdahulu. Senada dengan al-Zajjaj adalah imam al-Lihyani, ${ }^{10}$ Abul Hasan Ali bin Hazim (w. 215 H.) juga Manna' Khalil al-Qatthan, ${ }^{11}$ menurut mereka bahwa lafal Alquran itu mashdar mahmuz ( مصدر مهموز) ikut timbangan kata al-Fu'lanu (الفعلان) atau al-Ghufranu (الغفران) juga diambil dari kata qa-ra-a ( نر (ان ) ) dengan arti membaca ( نلا ( نا ( Dengan demikian, kata Alquran itu mashdar dari $q a-r a-a=$ yaq-ra-u = qur-an, qi-ra-ah dan qur'a-nan (قرا ا - يقر ا - قرءا, قراءة, قرانا), sehingga secara etimologi, al-Qur-an berarti bacaan, kemudian kata mashdar (kata kerja yang dibendakan) ini dibaca dengan isim maf'ul menjadi maqru', artinya sesuatu yang dibaca. Dengan demikian Alquran adalah sesuatu yang dibaca. Bahkan dalam fakta sejarah maupun bukti empirik menunjukkan bahwa di kolong langit ini, tidak satu pun bacaan yang jumlah pembacanya sebanyak pembaca Alquran, demikian kata tulisan Muhammad Amin Suma. ${ }^{12}$

\section{Imam Qiroah - Bacaan Alquran}

Bahasan yang sangat urgent adalah tentang bagaimana wahyu Alquran disampaikan, pewahyuannya kepada Rasulullah SAW oleh Allah SWT melalui malaikat Jibril as ternyata tidak sesederhana apa yang kita bayangkan, peringatan dini sudah Allah SWT sampaikan kepada nabi tatkala beliau dalam keadaan masih ketakutan setelah pertemuan perdananya dengan malaikat Jibril di gua Hira, disaat beliau tidur dengan berselimut tiba-tiba datang wahyu sebagaimana tercantum dalam Q.S (74). Al- Muzammil: “Sesungguhnya Kami akan menurunkan kapadamu Perkataan yang berat".

Qaulan Staqila - Ucapan yang berat, Proses penyampaian wahyu atau kalamullah ini bahkan ada cara yang dirasa sangat berat bagi Rasulullah SAW yaitu apabila wahyu itu disampaikan seperti bunyi lonceng. ${ }^{13}$ Dalam proses

\footnotetext{
${ }^{9}$ Subhi Shalih, Mabahist fi Ulum al-Qur'an, h. 18

${ }^{10}$ Subhi Shalih, Mabahist fi Ulum al-Qur'an, h. 19

${ }^{11}$ Manna' Khalil al-Qatthan, Mabahist fi Ulum al-Qur'an, (Riyadh: Mansyurat al-'Ashr al-

${ }^{12}$ Muhammad Amin Suma, Studi Ilmu-I lmu Al-Qur'an, (Jakarta: Pustaka Firdaus, 2000), j.

${ }_{13}$ Musthafa Muhammad 'Imarah, Jawahir al-Bukhari wa Syarh al-Qasthalani, (Indonesia: Maktabah Dar Ihya al-Kutub al-'Arabiyah, tth), h. 5
} Hadist, 1973 M./1393 H.), h. 20 1, h.21 
penyampaiannya, awalnya malaikat Jibril as hanya menggunakan satu huruf atau satu model dialek, kemudian Rasulullah SAW tidak henti-hentinya meminta kepada Jibril as agar menambahkannya sampai akhirnya berhenti diangka tujuh. Para ulama memahami kata tujuh huruf itu diantaranya dengan tujuh dialek suku arab saat proses nuzul Alquran yaitu suku Quraisy, Hudzail, Tsaqif, Hawazun, Kinanah, Tamim dan Yaman. ${ }^{14}$. Qiroah dalam arti suatu metode atau cara membaca Alquran oleh seorang imam dimana ia berbeda dengan lainnya. ${ }^{15}$ Qiroah dalam arti mazhab adalah suatu perkembangan sejarah dalam tata cara membaca Alquran. Malaikat Jibril as dalam mewahyukan Alquran kepada Rasulullah SAW yang dengan menggunakan tujuh huruf yang oleh para ulama pahami dengan tujuh dialek ini pernah menimbulkan sedikit ketegangan diantara para sahabat. Suatu ketika Umar bin Khatab shalat menjadi makmum dari sahabat Hisyam bin Hakim yang membaca surat al-Furqan, ternyata dipenilaian Umar apa yang dibaca sahabat Hisyam berbeda dengan apa yang Umar dapatkan dari Rasulullah SAW., maka segera Umar menyampaikan dan menanyakannya perihal bacaannnya sahabat Hisyam, setelah mereka bertemu dan menyampaikan permasalahannya dan Rasulullah SAW mendengarkan bacaan kedua sahabat tersebut, Rasululllah SAW bersabda: "Seperti itulah Alquran diturunkan". ${ }^{16}$

Setelah Rasulullah SAW wafat dan kekhilafahan dipegang oleh Abu Bakar al-Shidiq ra ada regulasi berupa kodifikasi terhadap Alquran. Kodifikasi ini didasarkan atas inisiasi dari Umar bin Khattab yang disampaikan kepada khalifah Abu Bakar al-shiddiq. Pada mulanya khalifah tidak mau menerima ide Umar ini karena dianggap "bid'ah". Inisiasi Umar bin Khattab ini sebagai wujud sifat hasasiyah (responsibilty) atas peristiwa dan terjadinya perang terhadap kelompok murtad di daerah Yamamah, peristiwa itu telah menyebabkan 70 sahabat penghafal Alquran (huffadl) gugur menjadi syuhada.

Di era Abu Bakar ini Alquran dikodifikasi tanpa pilih dan pilah model tulisan juga dialek bacaannya, semua diterima apabila dibuktikan dengan dua alat bukti sekaligus, yaitu hapalan dan tulisan. ${ }^{17}$ Akhirnya khalifah Abu bakar merespon usulan Umar bin Khattab dan memerintahkan juru tulis wahyu (Kuttab al-Wahyi) pada masa rasulullah SAW yaitu Zaid bin Stabit dengan timnya untuk segera melaksanakan dan mengkodifikasi Alquran. Setelah Abu bakar

${ }^{14}$ Manna' Khalil al-Qathan, Mabahist fi Ulum al-Qur'an, h. 158

${ }^{15}$ Diantara kitab yang secara khusus $m$ embahas tentang Qiroah Sab'ah secara mendetail dan dalam, baik dari sisi konten cara membaca ataupun silsilah sanad imam yang bersangkutan adalah Kitab "Al-Taisir fi al-Qiroat al-Sab'i) yang ditulis oleh al-Imam Abi Amr Ustman bin Sa'id al-Dani (w. 444 H.). Imam Abu Amr adalah salah seorang yang rasyihk fi ilm - sangat alim dalam bidang qiroah, beliau telah menulis tidak kurang dari 26 kitab yang terkait dengan masalah qiroah al-Qur'an ini. (Jeddah: Maktabah al-Haramain, tth).

${ }^{16}$ Manna' Khalil al-Qathan, Mabahist fi Ulum al-Qur'an, h. 157. Muhammad Ali al-Shabuni, Al-Tibyan fi Ulum al-Qur'an, (Beirut: Alam al-Kutub, 1985 M.-1405 H.), h. 216

17 Subhi Shalih, Mabahist fi Ulum al-Qur'an, (Beirut: Dar al-Ilm lil Malayin, 1988), h. 79 
wafat dan khilafah dipegang oleh Umar bin Khattab, terkait kodifikasi Alquran tidak ada perubahan apapun, perubahan baru ada pada masa khalifah ketiga, Usman bin Affan. Pada masanya, khalifah membuat regulasi agar tim yang dipimpin Zaid bin Stabit kembali menulis dan mengkodifikasi Alquran hanya dengan satu standar yaitu bahasa suku Quraisy, argument logis yang dikemukakan oleh khalifah bahwa Alquran diturunkan dengan standar mereka sebagaimana asal Nabi Muhammad SAW. Hasil kerja tim Zaid bin Stabit kemudian disebut dengan Rasm Usmani dan dijadikan sebagai Mushaf al-Imam (Buku Induk) yang harus dijadikan rujukan dalam penulisan Alquran berikutnya.

Benang merah pemahaman tentang kemutawatiran Alquran sebagaimana dijelaskan di atas, bisa juga kita temukan dengan cara kita mengikuti pendapat ulama yang mengggunakan metode ta'wil dalam memahami ayat dalam bentuk huruf tahaji (huruf hijaiyah yang secara independen dijadikan ayat pertama pada surat), seperti " ل " الم "yang dijadikan ayat pertama pada surat al-Baqarah;"18 bahwa huruf Alif diambil dari kata Allah, huruf Lam dari kata Malak Jibril sedangkan huruf Mim dari kata Muhammad; Ta'wil yang diberikan adalah bahwa Alquran cara penyampaiannya secara mutawatir dari Allah SWT kepada Jibril as dan terus kepada Rasulullah SAW yang kemudian menyampaikannya kepada para sahabat, secara bahasa dan bacaan semua sama tidak ada yang berubah dan berkurang sedikitpun.

Dari semua sahabat yang menerima pengajaran bacaan Alquran dari Rasulullah SAW yang terkenal selain dari empat khalifah al-Rasyidun (Abu Bakar al-Siddiq, Umar bin Khattab, Usman bin Affan dan Ali bin Abi Thalib) adalah; Abdullah bin Mas'ud, Salim bin Ma'qil, Mu'az bin Jabal, Ubay bin Ka'ab, Zaid bin Stabit, Abu Zaid bin al-Sakan dan Abu Darda. ${ }^{19}$ Setelah wilayah Islam meluas dan para sahabat menyebar serta masing-masing membawa cara membaca Alquran sesuai dengan yang mereka terima dari gurunya yaitu Rasulullah SAW., maka timbul pula akhirnya ragam cara membaca Alquran. Dari ragam cara membaca Alquran ini ada yang tidak bertahan sampai kini, tetapi ada juga yang bertahan sampai kita sekarang.

Eksistensi ragam bacaan yang sampai saat sekarang ini dikarenakan pola atau cara itu disamping dibaca terus menerus oleh si Qori (baca; imam) juga dilanjutkan oleh para muridnya dan lebih lagi ditulis sehingga dari generasi ke generasi bisa mempelajarinya. Dari sekian banyak imam qiroah yang terkenal adalah sebanyak tujuh orang, sehingga qiroahnya disebut dengan "Qiroah Sab'ah

${ }^{18}$ Hasil diskusi dengan beberapa fihak di forum kajian al-Qur'an.

19 Abdul Aziz al-Zamzami, Al-Iksir fi Tarjamah Nadzmi Ilmi al-Tafsir, (Semarang: Maktabah Thoha Putra, tth), h. 30-31 
- Tujuh Qiroah", ${ }^{20}$ Mereka adalah: imam Nafi', imam Ashim, imam Hamzah, imam Abdullah bin Amir, imam Abdullah bin Kastir, imam Abu Amr bin "Alla dan imam Ali bin al-Kisa'i.

\section{Indah dalam Baca Alquran}

Alquran dipandang sebagai bacaan secara umum boleh dibaca siapa, dimana dan kapan saja. Tetapi menjadi menarik tatkala Alquran dibaca dengan suara yang merdu, indah dan menggunakan lagu seperti yang marak belakangan ini. Pembacaan itu ada yang dilakukan oleh orang perorangan atau kelompok, baik secara tadarusan, ikhtiyari atau karena adanya event, atau malah dijadikan perlombaan dalam MTQ (Musabaqah Tilawatil Qur'an) baik ditingkat regional atau bahkan internasional. Membaca secara indah Alquran ternyata merupakan sunnah Rasulullah SAW, kita cermati Hadist riwayat imam Muslim dalam bab "Istihbab Tahsin al-Shaut bi Alquran", dari sahabat Abu Huraira h ra, Rasulullah SAW bersabda: ${ }^{21}$

“Dari Abu Hurairah, bahwa dia mendengar Rasulullah SAW bersabda: Allah tidak mengizinkan melantunkan membaca sesuatu dengan keras kepada Nabi kecuali dalam melantunkan (taghanniy) Alquran". (H.R. Imam Muslim).

Baru-baru ini tepatnya pada hari jum'at malam 15 Mei 2015 /27 Rajab 1436 H. jagad Nusantara dihebohkan oleh perhelatan akbar berupa Peringatan Isra' Mi'raj Nabi Muhammad SAW. Disebut perhelatan besar karena pelaksananya adalah Negara; semua pejabat tinggi Negara diundang dan hadir terutamanya Presiden ke 7 RI Bapak Ir. H. Joko Widodo juga Wapres Drs. H. Yusuf Kalla, tidak ketinggalan para menteri Kabinet Kerja terutama Menteri Agama Lukmanul Hakim Syaifuddin karena ini adalah gawean Kementerian Agama, bahkan hadir juga para Duta Besar.

Sangat menarik dan menggelitik untuk kita simak karena diantara rangkaian acaranya adalah pembacaan ayat suci Alquran dengan cara yang "tidak lazim", umumnya nagham atau lagu yang biasa dipakai untuk membaca Alquran adalah Bayati, Shoba, Hijaz, Nahawand, Rost, Jiharkah dan atau Sikah. Eh ini malah lagam yang nyentrik karena berupa lagam daerah asli Indonesia yaitu lagam Jawa yang dibawakan oleh Dr. Muhammad Yaser Arafat, MA. Alquran memang luar biasa, sebagai kitab suci umat Islam yang merupakan mayoritas penduduk Indonesia ini memang mengandung nuansa syair dan sajak, bahkan lebih indah karena semua kalimatnya ada nilai yang tidak dipunya oleh sajak apapun, tetapi Alquran bukan kitab syair dan sajak, dia adalah kitab hidayah. Mari kita perhatikan pada surat ke 112 (al-Ikhlas), surat ke 113 (al-

${ }^{20}$ Muhammad Ali al-Shabuni, Al-Tibyan fi Ulum al-Qur'an, (Beirut: 'Alam al-Kutub, cet. Pertama, 1985 M./1405 H.), h. 233. Abdul Aziz al-Zamzami, Al-Iksir fi Tarjamah Nadzmi Ilmi al-Tafsir, (Semarang: Maktabah Thoha Putra, tth), h. 32

${ }^{21}$ Imam Muslim, Shahih Muslim, (Mesir: Isa al-Babi al-Halbi wa Syirkah, tth), h. 317 
Falaq) juga surat yang ke 114 yang merupakan surat terakhir Alquran (an-Nas). Namun begitu Alquran bukanlah kitab syair yang boleh kita baca selayaknya syair, bahkan lebih dari itu tidaklah layak bagi seorang nabi untuk bersyair, bahkan syair bukanlah ucapan para rasul, demikian disampaikan oleh Syaikh Hamami Zadah dalam kitabnya yang khusus tentang surat Yasiin, ${ }^{22}$ ini langsung jaminan dari Allah SWT sebagaimana firman-Nya:

“Dan Kami tidak mengajarkan syair kepadanya (Muhammad) dan bersyair itu tidaklah layak baginya. Al Quran itu tidak lain hanyalah pelajaran dan kitab yang memberi penerangan"(Q.S. Yasin:36:69).

Sebagai teks bacaan, Alquran secara bahasa tentunya sama dengan bacaan-bacaan pada umumnya, boleh dibaca kapan dan dimana saja begitu pula dalam keadaan apa saja, namun demikian ia menjadi tidak sama dan bahkan memang harus tidak sama dan berbeda dengan teks bacaan apapun dilihat dari Alquran sebagai Kalamullah. Perspektif ini dapat dilihat dari definisi Alquran yang disampaikan oleh para ulama, Alquran adalah ${ }^{23}$ "Kalamullah yang mu'jiz (bernilai mu'jizat)", diturunkan kepada nabi Muhammad SAW seorang penutup para nabi dan rasul, melalui perantara malaikat Jibril al-Amin, ditulis dalam mushaf, disampaikan kepada kita secara mutawatir, dinilai ibadah membacanya, diawali dengan surat al-Fatihah dan diakhiri dengan surat al-Nas". ${ }^{24}$ Dengan melihat dan mengikuti definisi tentang arti Alquran secara terminology yang telah disampaikan di atas, kita garis bawahi kata," disampaikan kepada kita secara mutawatir". Kata mutawatir secara umum berarti penyampaian sesuatu secara sama oleh semua generasi sehingga tidak mungkin adanya pembelokan atau kebohongan. ${ }^{25}$ Malaikat Jibril as itu menerima wahyu Alquran dari Allah SWT secara langsung secara lafal dan makna dengan cara yang khusus, kemudian malaikat Jibril menyampaikannya kepada nabi Muhammad SAW sama persis dan persis sama sebagaimana beliau terima dari Allah SWT., dalam hal ini malaikat Jibril bukan sekedar menghafalnya dari Lauh al-Mahfudh, apalagi hanya menyampaikan arti atau maksudnya saja. ${ }^{26}$ Sehingga Alquran ini benar-benar murni kalam Allah SWT. Kita perhatikan pernyataanNya kepada Muhammad bin Abdullah, Rasulullah. SAW. “Dan Sesungguhnya

\footnotetext{
${ }^{22}$ Hamami Zadah, Tafsir Surah Yasiin, (Surabaya, Indonesia: Maktabah Dar al-Ilm), tth., h. 26

${ }^{23}$ Muhammad Ali al-Shabuni, Al-Tibyan fi Ulum al-Qur'an, (Beirut: 'Alam al-Kutub, cet. Pertama, 1985 M./1405 H.), h. 8

${ }^{24}$ Lihat dalam Manna' Khalil al-Qathan, Mabahist fi Ulum al-Qur'an, h. 20-21. Muhammad Ali al-Shabuni, Al-Tibyan fi Ulum al-Qur'an, (Beirut: 'Alam al-Kutub, cet. Pertama, 1985 M./1405 H.), h. 8

25 Hafidz Hasan al-Mas'udi, Minhah al-Mughist fi Ilm Musthalah al-Hadist, (Semarang: Pustaka al-Alawiyah, tth.), h. 10. Lihat juga pada, Sayyid Muhammad bin Alawi bin Abbas alMaliki al-Makki al-Hasani, Al-Minhal al-Latif fi Ushul al-Hadist al-Syarif, (Malang: Haiah al-Shofwah, tth.), h. 94

${ }^{26}$ Lihat Manna' Khalil al-Qathan, Mabahist fi Ulum al-Qur'an, h. 35-36
} 
kamu benar-benar diberi Al-Qur'an dari sisi (Allah) yang Maha Bijaksana lagi Maha mengetahui". (Q.S. al-Naml:27:6)

Pada ayat yang lain, juga dapat kita pahami bahwa Rasulullah SAW hanya mengikuti bacaan Alquran yang diterimanya, tidak lebih juga tidak kurang, kita perhatikan firman Allah SWT. Dalam al-Bayyinat, surat ke 75 pada ayat 17 dan 18. "Sesungguhnya atas tanggungan Kamilah mengumpulkannya (di dadamu) dan (membuatmu pandai) membacanya. Apabila Kami telah selesai membacakannya maka ikutilah bacaannya itu".

Taqdir Allah SWT. yang telah menentukan manusia sebagai mahkluk berakal dan berbudaya disamping juga dianugerahi nafsu, dengan modal seperti itu manusia di dunia ini dianugerahi oleh penciptanya mempunyai dwi fungsi sekaligus yang ternyata hal itu tidak dianugerahkan kepada makhluk-mahkluk lainnya, yaitu sebagai hamba Allah (Abdullah) sekaligus wakil Allah (Khalifatullah). Dalam mengemban fungsinya ternyata manusia selalu berkecenderungan membuat sesuatu yang baru (tahdist).

Bacaan Alquran adalah hal yang sacral dan bersifat ta'abbudi, dan sampainya kepada kita adalah secara mutawatir dari sejak diturunkan kepada Jibril as dan Rasulullah SAW terus kepada para sahabat dan sampai kepada kita saat ini bahkan sampai titik generasi terakhir manusia nanti adalah sama persis dan persis sama. Tetapi dalam masalah nagham-lagam-lagu Rasulullah SAW tidak pernah mengajarkannya kepada para sahabat, dengan demikian nagham adalah hasil ijtihadi ulama. Kalau perpsektif ini yang kita pakai, maka barang siapa yang membaca Alquran dengan menggunakan lagu adalah bagian dari ibadah muamalah, artinya ibadah tersebut tidak bersifat hubungan langsung antara seorang manusia dengan Allah sebagai Tuhannya. Dalam ibadah muamalah Allah SWT dan juga Rasulullah SAW hanya mengatur secara global dan umum saja disini berarti bacaan Alquran, sedangkan bagaimana nagham, lagam atau lagu diserahkan kepada kreatifitas manusia.

Hal ini sejalan dengan arti muamalah itu sendiri yang secara etimologi terambil dari kata عامل - يعامل - معاملة yang ternyata isim mashdar (kata kerja yang dibendakan) dari kata عم y yang mendapat tambahan huruf alif, maka hal itu berarti berfungsi musyarakah bain al-istnaini (adanya hubungan kerja antara dua fihak). ${ }^{27}$ Kata muamalah didefinisikan sebagai ibadah yang tidak secara langsung berhubungan dengan Allah SWT tetapi berupa adanya interaksi antara manusia dengan sesama atau lingkungannya. Dalam muamalah kaidah fikih fersi imam Muhammad bin Idris al-Syafi'i (imam Syafi'i) dan banyak diikuti oleh para

27 Muhammad Ma'shum bin Ali, Al-Amstilah al-Tashrifiyah, (Semarang: Pustaka alAlawiyah), tth., h. 14-15 
- الاصل فى المعاملة الاباحة حتى يجد الاليل على تحريمها بال Asal dalam muamalah adalah ibahah - boleh sampai ada dalil yang mengharamkannya".

Peringatan Isra' Mi'raj Nabi besar Muhammad SAW yang dilaksanakan di Istana oleh pemerintah RI dalam sesi Tilawah Alquran sang Qori' menyampaikannya dengan lagam jawa. Alquran adalah sesuatu yang indah (malih), ia akan bertambah indah apabila dibaca dan disampaikan dengan indah. Allah SWT juga indah bahkan Maha Indah suka kepada yang indah, begitu pula Rasulullah SAW sangat mencintai keindahan. Status hukumnya adalah sunnat membaca Alquran dengan suara bagus dan merdu, bahkan menurut imam Syarafuddin al-Nawawi juga sunnat meminta atau menyuruh orang yang bagus suaranya untuk membacakannya. ${ }^{29}$ Karena suara yang merdu akan lebih mendatangkan kekhusyuan dan kenyamanan pendengar sehingga lebih menyampaikan misi Alquran itu sendiri. Rasulullah SAW memberikan apresiasi kepada sahabat Abu Musa Asy'ari sebagai salah seorang yang mendapat anugerah suara yang merdu laksana serulingnya nabi Dawud as. Kata tartil adalah bahasa umum yang dipakai oleh Allah SWT dalam memerintahkan kepada Rasulullah SAW saat membaca al- Qur'an : ورتل القران ترتيلا Al Qur'an itu dengan tartil (pen. perlahan-lahan)"'.(Q.S. al-Muzammil:73:4). Banyak hadist yang secara spesifik Rasulullah SAW memerintahkan agar kita زينوا 30 30 أن Hiasilah Alquran dengan suara kalian. (H.R. Ibn Hibban dari sahabat Barra bin Azib). Dalam kesempatan yang lain, beliau juga bersabda; حسنوان بان dengan suara AlquranBuatlah indah - القران باصو اتكم, فان الصوت الحسن يزيد القران حسنا kalian, karena sesungguhnya suara yang indah membuat Alquran tambah indah. (H.R. Darimi dari sahabat Barra bin Azib).

\section{Lagu Baca Alquran}

Keindahan Alquran akan tampak lebih nyata apabila ia dibaca secara benar dan dengan suara merdu, betapa hati dan perasaan sering hanyut karena merasa nyaman, tentram dan tidak jarang tanpa sadar mulut sipendengar bergumam الله dengan hati tergetar saat lantunan ayat suci itu dibaca. Kalau kita perhatikan pada acara Isra' Mi'raj di Istana yang telah menimbulkan pro dan kontra. Pada satu sisi para tamu undangan betapa banyak yang termangu-

${ }^{28}$ Muhammad Shidqi bin Ahmad al-Burniu, Al-Wajiz fi Idlaih Qawaid al-Figh al-Kulliyah, (Riyadh:Muassasah al-Risalah1983 M.-1404H.), h. 109. Muhammad Jamaluddin bin Ahmad, Al'Inayah fi al-Qawaid al-Fiqhiyyah, (Jombang:Al-Muhibbin, 1412H.), h. 28.

29 Abdurrahman al-Suyuthi, Al-Itqan fi Ulum al-Qur'an, (Beirut: Dar al-Fikr, 1996M./1416H.), j. 1, h. 337

${ }^{30}$ Imam Ibn Hibban, Shahih Ibn Hibban, (Maktabah Syamilah: Shahih Ibn Hibban, j. 3. H. 25).

\footnotetext{
${ }^{31}$ Imam al-Darimi, Sunan al-Darimi, (Maktabah Syamilah: Sunan al-Darimi, j. 4, h. 2194).
} 
mangu mendengarkan qiroah Alquran dengan lagam Jawa tanda mereka menikmati dan setuju, seolah mereka bilang ok, why not?

Dibagian lain "diluaran sana" banyak yang bersungut-sungut tanda tidak sepaham dan tidak setuju dengan apa yang terjadi di Istana. Mereka bahkan ada yang mau mengusulkan agar menteri Agama diganti saja, dianggap telah melecehkan agama. Lantas bagaimana sebenarnya Nagham - lagam - lagu dalam membaca Alquran? Ilmu yang mengajarkan benar dan juga keindahan dalam membaca Alquran disebut Ilmu Tajwid.

Kata tajwid berasal dari kata: جود - يجود - تجويد - jawwada - yujawwidu tajwid, yang berarti membuat indah. Ilmu tajwid adalah ilmu yang mempelajari tentang bagaimana cara mengucapkan huruf hijaiyah sesuai dengan aturan yang semestinya, mengetahui panjang juga pendeknya bacaan, jelas (idzhar), idgham, tafkhim-tarqiq (tebal-tipis), waqaf (berhenti), imalah (tengah antara fathah dan kasrah) juga ihkfa (samar) dan lainnya. Ilmu ini tidak bisa dipelajari hanya dengan membaca kitab atau buku, tetapi harus bermusyafahah - belajar secara langsung dengan guru, demikian dikatakan oleh Manna' Khalil Qatthan yang mengutip pendapatnya Ibn al-Jaziri yang oleh al-Suyuthi disebutnya sebagai syaikh syuyukhina-guru para guru kita (imam qiroah). ${ }^{32}$

Huruf hijaiyah yang dipakai dalam menyusun lafal dan kalimat bahasa Arab yang ternyata juga dipakai oleh Kalamullah Alquran memang mempunyai karakteristik sangat berbeda dengan bahasa apapun di kolong jagad. Hal itu bisa dilihat dari banyak sisi; bisa dari gramatika (nahwu), bisa juga dari kekayaan susunan asal dan perubahan kata yang ternyata punya arti sangat jauh berbeda dari asal katanya (sharaf); belum lagi lafal yang kelihatan sama cara menulis dan juga hurufnya tetapi berbeda harakat, maka berbeda bunyi dan juga artinya; sekedar contoh:33 kata قدر ; apabila kita ba ca Qa-da-run artinya ukuran, apabila kita baca qid-run artinya panci, tetapi begitu kita baca Qad-run maka artinya adalah kemuliaan atau keagungan dan masih sangat banyak yang lainnya, belum lagi dari sisi ada tidaknya tambahan pada suatu lafal yang juga pasti merubah arti yang dikandungnya.

Alquran dilihat dari bacaan dan cara membacanya secara tartil adalah bersifat mutawatir, ada dan harus tetap adanya sejak zaman awal nuzulnya sampai kapanpun sebagai dijelaskan di atas, tetapi membacanya secara indah dengan lagu, nagham, atau lagam maka adanya jauh setelah proses nuzul Alquran itu selesai, dengan argumentasi logika ini, maka adanyanya nagham atau lagam tidak qath'i karena tidak mutawatir. Karena nagham atau lagu ini

\footnotetext{
32 Manna' Khalil al-Qathan, Mabahist fi Ulum al-Qur'an, h. 188. Abdurrahman Al-Suyuthi, Al-Itqan fi Ulum al-Qur'an, (Beirut: Dar al-Fikr, 1996 M.-1416 H.), j. 1, h. 236.

${ }^{33}$ Lihat dalam Kamaluddin Nurdin Marjuni, Kamus Syawarifiyyah, (Jakarta: Ciputat Press dan Ma'had Syawarifiyyah, 2007), h. 471-472.
} 
tidak qath'i, maka ia diposisikan sebagai bagian dari ibadah muamalah, dan karenanya menurut penulis berlakulah kaidah sebagaimana disebutkan di atas.

Memang konsekwensi logis dalam usaha memperluas wilayah dakwah Islamiyah para sahabat kemudian menyebar ke seluruh pelosok negeri dengan membawa Qira'at masing-masing. Hal ini menyebabkan berbeda-beda juga ketika Tabi'in mengambil Qira'at dari para Sahabat. Demikian halnya dengan Tabiut-tabi'in yang berbeda-beda dalam mengambil Qira'at dari para Tabi'in. ${ }^{34}$ Kendati demikian ada dasar teori akademik yang disepakati sebagai dasar rancang bangun untuk menilai suatu qiroah itu shahih dan tidaknya, serta boleh diamalkan dalam kehidupan baik ketika shalat atau hanya tadarusan, baik dilakukan secara individual atau secara kolektif. Para ulama menetapkan tiga syarat sah dan diterimanya qiraat. ${ }^{35}$ yaitu :1) Sesuai dengan salah satu kaidah bahasa Arab.2) Sesuai dengan tulisan pada salah satu mushaf Usmani, walaupun hanya tersirat. 3) Shahih sanadnya.

Kendati ilmu qiraat berhubungan dengan pelafalan ayat-ayat Alquran, ia tidak memiliki kaitan dengan melagukan bacaan Alquran. Khusus untuk masalah melagukan Alquran, dijelaskan dalam ilmu nagham, yaitu ilmu tentang seni membaca Alquran. Eksistensi dan keberadaan ilmu nagham secara ekplisit disebutkan dalam surat Al-Muzzammil ayat 4 di atas. Di berbagai wilayah negeri Islam berkembang aneka ragam seni membaca Alquran. Seni baca indah atau nagham yang dikenal adalah; Nahawan, Bayati, Hijaz, Shaba, Ras, Jiharkah, Syika, dan lainnya.

Semua jenis lagu atau irama itu tidak ada kaitannya dengan ilmu Qiraat Sab'ah seperti yang dijelaskan di atas. Ilmu nagham ini semata-mata hanya merupakan seni membaca secara malih (indah) terkait dengan bagaimana melafalkan ayat Alquran. Menurut penelusuran data, pada umumnya, para pembaca Alquran dari Mesir yang membawa seni baca Alquran ke Indonesia. Mereka mengajarkan berbagai macam lagu dan memberikan beragam variasinya serta membuat harmoni yang khas. Seni seperti itulah yang sering kali diperlombakan dalam acara Musabaqah Tilawatil Qur'an (MTQ).

Nagham-lagam adalah merupakan salah satu bentuk ekspresi seni dalam Islam. Nagham ini telah tumbuh sejak lama. Ibnu Manzur menyatakan bahwa ada dua teori tentang asal mula munculnya naghom Alquran. Pertama, nagham Alquran berasal dari nyanyian nenek moyang bangsa Arab. Kedua, nagham terinspirasi dari nyanyian budak-budak kafir yang menjadi tawanan perang. Kedua teori tersebut menegaskan bahwa lagu-lagu dalam membaca Alquran berasal dari khazanah tradisional Arab. Dengan teori ini pula, ditegaskan bahwa

\footnotetext{
${ }^{34}$ Abdul Aziz al-Zamzami, Al-Iksir fi Tarjamah Nadzmi Ilmi al-Tafsir, (Semarang: Maktabah Thoha Putra, tth), h. 28-31

35 Jalal al-Din al-Suyuthi, Abd. Al-Rahman, Al-Itqan fi Ulum al-Qur'an, (Beirut: Dar al-Fikr, 1996 M.-1416 H.), j. 1, h. 236-238
} 
lagu-lagu dalam membaca Alquran idealnya bernuansa irama Arab. Dalam tautan sejarah, bahwa seni baca Alquran baru menampakkan semangat dan geliatnya pada awal abad ke-20 M. yang berpusat di Makkah dan Madinah serta di Indonesia.

\section{Kesimpulan}

Alquran secara etimologi yang berarti bacaan pada dasarnya bisa diperspektifkan sama dengan apapun nama bacaan, baik dari sisi bahasa ataupun cara membacanya. Namun demikian sebagai Kalamullah Alquran mempunyai nilai yang amat sangat berbeda dengan kalam atau ucapan siapa dan apapun. Sebagaimana diinformasikan sendiri oleh shohibul kalam Allah Jalla Jalaluhu bahwa nabi Muhammad SAW hanya diperintahkan menyampaikan apa adanya Alquran itu sebagaimana beliau terima sebagaimana bunyi Q.S. AlBayyinat (75): 18 di atas. Maka dengan dasar ayat tersebut, menjadi tiada berhak siapapun dan atas nama apapun untuk mengubah bacaan Alquran, baik dengan cara menambah ataupun mengurangi apalagi menghilangkan sebagian. Bacaan Alquran harus Tasalsul sanad-bersambung dan tidak terputusnya sanad, inilah yang lazim disebut dengan mutawatir.

Setiap muslim pasti sepakat bahwa Alquran kitab suci yang indah "syai'un malih", ia akan menjadi semakin indah kalau dibaca secara indah dengan menggunakan nagham atau lagam dan suara yang merdu. Secara bacaan Alquran itu bersifat mutawatir artinya sejak dari awal malaikat Jibril menerimanya dari Allah SWT yang kemudian disampaikan kepada Rasulullah SAW begitu pula rasul dalam menyampaikan kembali kepada para sahabat dan begitu seterusnya dalam lintas sejarah pergantian dan berbedanya generasi adalah sama. Menjadi kebanggaan tersendiri apabila seseorang dianugerahi suara yang merdu sebagaimana Rasulullah SAW memberikan apresiasi kepada sahabat Abu Musa al-Asy'ari, kontra produktif bisa saja terjadi apabila nagham yang dipakai tidak lagi nagham Arab sebagai pakem kelaziman tetapi justru nagham atau lagam ajam (non arab) sebagaimana yang pernah terjadi.

Hemat penulis, sebagai proses tafhim dan memberikan pencerahan kepada masyarakat, Alquran harus dipahami dari dua sisi sekaligus yaitu kontek bacaan dan cara membacanya. Dilihat dari sudut pandang bacaan, maka Alquran adalah mutawatir sedangkan cara membacanya dengan nagham adalah bagian dari olah rasa manusia dalam keinginannya lebih bisa membuat Alquran semakin indah, sehingga membaca Alquran menggunakan nagham adalah bagian dari ibadah muamalah. Sebagai bagian dari ibadah muamalah, maka baginya juga berlaku kaidah muamalah yaitu bahwa "asal segala sesuatu adalah boleh sampai ada dalil yang melarangnya". Wallahu a'lam bi al-Shawab. 


\section{Daftar Pustaka}

Aji, Ahmad Mukri. Urgensi Maslahat Mursalah Dalam Dialektika Pemikiran Hukum Islam, Bogor: Pustaka Pena Ilahi, 2012.

Aji, Ahmad Mukri. Kontekstualisasi Ijtihad Dalam Diskursus Pemikiran Hukum Islam di Indonesia, Bogor: Pustaka Pena Ilahi, 2010. Al-Bukhari, Imam Ismail bin Ibrahim bin Mughirah, Shahih Bukhari, (Mesir: Dar Kutub)

Al-Burniu, Muhammad Shidqi bin Ahmad, Al-Wajiz fi Idlaih Qawaid al-Figh alKulliyah, (Riyadh: Muassasah al-Risalah), 1983 M./1412 H.

Al-Darimi, Imam, Sunan al-Darimi, Maktabah Syamilah: Sunan al-Darimi, j. 4.

Al-Hasani, Sayyid Muhammad bin Alawi bin Abbas al-Maliki al-Makki, AlMinhal al-Latif fi Ushul al-Hadist al-Syarif, (Malang: Haiah al-Shofwah).

Muslim, Imam, Shahih Muslim, (Mesir: Isa al-Babi al-Halbi wa Syirkah).

Al-Mas'udi, Hafidz Hasan, Minhah al-Mughist fi Ilm Musthalah al-Hadist, (Semarang: Pustaka al-Alawiyah).

Al-Qatthan, Manna' Khalil, Mabahist fi Ulum Alquran, (Riyadh: Mansyurat al'Ashr al-Hadist, 1973 M./1393 H).

Al-Samarqandi, Nashr bin Muhammad al-Hanafi, Qathr al-Ghaist fi Syarh Abi Laist, (Surabaya: Said bin Nabhan wa Auladuh).

Al-Sanusi, Muhammad, Hasyiyah al-Dasuqi 'ala Um al-Barahain, (Singapura, Jeddah: Al-Haramain).

Al-Syarqawi, Al-Syarqawi 'ala al-Hud-Hudi, (Semarang: Maktabah wa Matba'ah Keluarga).

Al-Shabuni, Muhammad Ali, Al-Tibyan fi Ulum Alquran, (Beirut: 'Alam al-Kutub, cet. Pertama, 1985 M./1405 H.).

Suma, Muhammad Amin, Studi Ilmu-Ilmu Alquran, (Jakarta: Pustaka Firdaus, 2000.

Subhi Shalih, Mabahist fi Ulum Alquran, (Beirut: Dar al-Ilm lil Malayin).

Al-Suyuthi, Abdurrahman, Al-Itqan fi Ulum Alquran, (Beirut: Dar al-Fikr, 1996M./1416H.).

Hibban, Imam Ibn Hibban, Shahih Ibn Hibban, (Maktabah Syamilah: Shahih Ibn Hibban, j. 3.).

Imarah, Musthafa Muhammad, Jawahir al-Bukhari wa Syarh al-Qasthalani, (Indonesia: Maktabah Dar Ihya al-Kutub al-'Arabiyah).

Kamaluddin Nurdin Marjuni, Kamus Syawarifiyyah, (Jakarta: Ciputat Press dan Ma'had Syawarifiyyah), 2007

Muhammad Ma'shum bin Ali, Al-Amstilah al-Tashrifiyah, (Semarang: Pustaka alAlawiyah).

Muhammad Jamaluddin bin Ahmad, Al-'Inayah fi al-Qawaid al-Fiqhiyyah, (Jombang: Maktabah al-Muhibbin), $1412 \mathrm{H}$

Al-Zamzami, Abdul Aziz; Al-Iksir fi Tarjamah Nadzmi Ilmi al-Tafsir, (Semarang: Maktabah Thoha Putra). 